\title{
Risk assessment of noise pollution by analyzing the level of sound loudness resulting from central traffic in Shiraz
}

\author{
Hadi Negahdari $^{(\mathbb{D}}$, Sirus Javadpour ${ }^{2 *}$, Faramarz Moattar ${ }^{1}$, Hashem Negahdari ${ }^{3}$ \\ ${ }^{1}$ Department of Environmental Engineering, Faculty of Natural Resources and Environment, Science and Research Branch, Islamic \\ Azad University, Tehran, Iran \\ ${ }^{2}$ Material Science and Engineering Department, School of Engineering, Shiraz University, Shiraz, Iran \\ ${ }^{3}$ Department of Civil Engineering, School of Engineering, Islamic Azad University, Shiraz Branch, Shiraz, Iran
}

\section{Abstract}

Background: Today, the effects of environmental pollution on human life and human needs, which reduces the level of community health caused by traffic noise in large cities, are clearly visible by creating irritation and pathogenic conditions. The aim of this study was to assess the risk of noise pollution resulted from central traffic in Shiraz by analyzing its indicators and related components.

Methods: By specifying the high traffic jam in Shiraz, the sound and its frequency in 156 points of the city were analyzed using a sound analyzer (Tes-1358C model). The sound pressure levels $\left(\mathrm{L}_{\mathrm{A}}\right.$ and $\left.\mathrm{L}_{\mathrm{p}}\right)$ and the one and one-third octave band were continuously measured in A and C networks. Then, data were extracted and analyzed using Excel 2016 and Minitab 18.1. Eventually, phon and sone indexes were calculated for the heavy traffic jam in some of the central streets of Shiraz and the results were statistically calculated and their charts were prepared with comfort disturbance ranges.

Results: The highest harmful frequency of traffic in Shiraz was $50 \mathrm{~Hz}$ and $83.3 \mathrm{~dB}$. The sound pressure level ranged from 70 to $92.7 \mathrm{~dB}$ in network $\mathrm{A}$ and $87.8 \mathrm{~dB}$ in network $\mathrm{C}$. The maximum sound level was 87 phon and the maximum sone was 26 at 14 stations.

Conclusion: According to the results, the sound pressure levels exceeded the environmental standards of Iran and the values of phon and sone were higher than the standard of comfort at night and day. Keywords: Noise pollution, Environmental pollution, Loudness perception, Health risk assessment, Shiraz.

Citation: Negahdari H, Javadpour S, Moattar F, Negahdari H. Risk assessment of noise pollution by analyzing the level of sound loudness resulting from central traffic in Shiraz. Environmental Health Engineering and Management Journal 2018; 5(4): 211-220. doi: 10.15171/EHEM.2018.29.
Article History:

Received: 5 August 2018

Accepted: 3 November 2018

ePublished: 20 November 2018

*Correspondence to:

Sirus Javadpour

Email: Javadpor@shirazu.ac.ir

\section{Introduction}

Today, with the rapid advances in technology and increasing human needs, the kind of popular look to sound has changed. Some people enjoy loud sound in their jobs (such as musicians), on the other hand, some find it annoying. One of the most damaging and neglected factors in the environment, life, and work is noise pollution (1). One of the major problems of large cities in Iran is noise pollution. Recent studies have shown that in Tehran and other large metropolitan areas of Iran, the level of noise pollution has reached an intolerable level so that the residents of these cities should gradually think about providing hearing protectors to protect their ears from loud sound, while attending the city, or accept that they gradually lose their hearing ability (1). Noise pollution is not a new issue for large cities, and public health authorities warned that the level of noise pollution and its consequences are raising above the tolerance level in large cities.

Noise-induced hearing loss (NIHL) is known as an occupational disease in the world (2). The living conditions of humans are such that they interact with noise daily based on their activity and place of live (3). According to the Environmental Protection Agency (EPA), the balance of sound level meter should not exceed $35 \mathrm{~dB}$ at night and $45 \mathrm{~dB}$ in day (3). Studies have shown that the average sound pressure level in different parts of a hospital is 56.3 $\mathrm{dB}$ (4). Using noise maps, noise pollution level (NPL), and traffic noise index (TNI) can help intelligent traffic control planning, because these maps can represent the movement of people in different times and parts of a city (5).

From a practical point of view, scientists have progressively realized that noise pollution in large cities of Iran 
was higher than the Iran's Environmental Protection Organization (IEPO) standard such as Kashan, Zahedan, and Qom (6-8). According to a study by Mosaferi et al, the main cause of noise pollution in Tabriz is motor vehicles, thus, control procedures are necessary in this area (9). In a similar study conducted in Tehran, the analysis of sound pressure level showed that the equivalent sound level (Leq) in all regions during night, the day average sound level only in the Simetry Jey area, and the night average sound level in all regions except Dorahi Ghopan, were more than the acceptable one (10). According to Safari Variani et al study, exposure to high levels of noise can affect the businesses and people who are exposed to high noise levels for a long time in the area, including traffic police. High noise levels also increase mental fatigue, and reduce tolerance thresholds and focus in the ear of traffic police, business activists, and drivers $(11,12)$. Sound is a sociopolitical phenomenon that plays an important role in the quality and socio-economic structure of societies. So, the risk assessment of traffic plans is necessary (13). According to a study conducted in Zanjan, clock changes completely follow the traffic habits of people and traffic loads in the commercial areas of the cities (14). In various health studies, the effects of noise pollution on heart rate (15), blood pressure and cardiovascular disease, especially in high-noisy industries (16), neuroticism, sensitivity, and creating extroversion to low frequencies (17) in hot climates was investigated and it was known as an effective elements on health factors and cognitive performance. Noise pollution has special physiological effects on sensitive groups such as pregnant women (18). In another study on the effects of sound on the health of outdoor workers such as taxi drivers (19), it was revealed that it created mistakes in the reaction time and sensitive occupations (20), high levels of sound pressure in large and medium cities (21), and occupational hearing loss at low frequencies (22).

The noise level in low and high traffic areas in Shiraz city was higher than the standard levels that increases the sleep disorders and decreases the quality of people's life (23). Although air pollution and traffic jams and droughts over the past few years have left no place for concern about noise pollution, but if this situation continues, in the near future, noise pollution will also be on the brink of a crisis, as climate and drought are now among the top ecological and critical issues. Noise pollution is one of the neglected aspects of environmental pollution. According to the reports of the World Health Organization (WHO) and other related organizations such as the International Labour Organization (ILO), National Institute for Occupational Safety and Health (NIOSH), and American Conference of Governmental Industrial Hygienists (ACGIH), noise pollution is the third most harmful and dangerous type of pollution in large cities after air and water pollution (24-26). Therefore, this study was performed due to the importance of this issue.
In developed countries, for controlling the noise, a minimum level of relaxation in the front view of the building called "quiet side", is provided by compiling the requirements for building insulation and decreasing the level of sound pressure to 5 to $10 \mathrm{~dB}$ and no sound increase more than $55 \mathrm{~dB}$ (17), so that the difference between a loud and slow sound be at least $10 \mathrm{~dB}$ as a base. However, there is growing evidence that the indoor sound environment for residents of homes adjacent to hightraffic areas, especially for those living in apartments, is discomfort (27).

Some disorders especially sleep disorders as the first stage of the negative effects of the environmental noise penetration to the residential homes are of great importance. But other sleep indicators (e.g., heartbeat changes, sleep stages, etc.) have shown complex relationships with the value and level of sound pressure (28). There is some evidence that some traffic events commonly do not occur at night (29). It is worth noting that noise events at the end of sleep have a greater effect on the overall quality of sleep and as a result, traffic in the morning has the most important effect (29). Today, according to the modern urban perspective, people's perceptions of the concept of sound have been changed and the indoor noise at home has changed with the modernization of life. Therefore, sound planning in a modern city involves new evaluations and comments to accommodate these differences. The quality of sound in public space is identified and evaluated as an integral part of the urban environment within the scope and specific uses imposed by the urban space. Physical characteristics of the environmental sound required to assess this quality far exceeds the overall noise level and includes spectrum and structure (30-32). Today, the efforts to develop appropriate physical indicators are continuing, but it seems that physical indicators are never enough, it means that a listener who is dependent on sound is very important (33).

Given the fact that the urban public spaces are often located in the center of city, overall quality of sound including traffic noise, mobile phone, people's talks, etc., must be evaluated. An important reason for conducting this study is that the availability of high-quality urban spaces, for example, a green and quiet space in the city that helps to the health of urban citizens, has not been evaluated by the authorities in modern perspectives in the cities of Iran. Today, in particular, some architects have suggested the potential for mental reconstruction by creating natural relaxation areas. Therefore, by considering the environmental goals, the risk assessment of traffic noise has become more vital in urban management and planning.

Various studies have discussed the problem of pathogenicity and discomfort and annoyance due to noise pollution, and what contemporary society is facing seriously is that if the authorities do not react to reduce and control noise pollution, the use of hearing protection 
equipment (e.g., earplug or earmuff) will become inevitable for people especially those who have industrial occupation in the near future. Therefore, in order to find the fundamental solutions for control and reduction of noise pollution in terms of engineering and management, it is necessary to identify the indicators and criteria for assessing the risk of noise pollution in the majority of large cities and metropolitan areas. So far, many studies have been conducted on health issues and harmful effects of noise pollution on health and work efficiency, but few studies have been conducted on sound loudness. The aims of this study were to measure the frequency and loudness of the traffic noise and evaluate the traffic-induced noise pollution.

This study is the first one evaluated loudness of the urban traffic noise in Shiraz. Acoustic analyses are used in many areas. The common goal of many acoustic analyses is to study the sound characteristics emitted from a source, to find how it is propagated in the environment, and in some cases, to adapt the acoustic conditions to what is required by local standards or laws (34). One of the ways for performing acoustic analysis is to examine related criteria such as sound loudness. In this regard, it is necessary to use analytical indicators such as sound loudness (sone) and phon according to the global criteria In this study, for the first time, these valuable criteria were used to assess the risk of noise pollution in the central and high traffic areas of Shiraz at different hours of the day and night.

\section{Materials and Methods}

This study was performed on a number of the most crowded and heavy traffic streets and highways in the downstream and center of Shiraz along with 6 streets connected to the main road that have heavy traffic during the day. Measurements were completed on 2016 July to 2017 December at 156 measuring stations. Totally, 156 urban centers were selected acoustically for businessresidential situations along roads, sidewalks, and shopping areas and at least two points along each of the main and secondary streets and the city center. The majority of the population is inhabited in regions 6,7 , and 8 , and the central part of Shiraz including areas 1, 2, 4, and 5, which is the more heavily populated, has the highest level of noise pollution.

As shown in Figure 1, the population size of the passengers and pedestrians at public transportation stations of Shiraz was higher at morning peak hours in the areas 1 , 3 , and 6 . This makes it necessary to protect residents and workers from noise pollution caused by urban traffic (see Figure 1B).

\section{Sound loudness level (Sone)}

Sound loudness is a mental issue that reflects the power of perception of sound by the ear. In other words, it is the intensity of sound. The intensity of sound should be focused by the sensitivity of the ear to the specific sound frequencies. This kind of sensitivity is the information that exists in the narrow curves for the human ear $(3,34)$. A general rule for sound loudness is that the power should be increased by about ten times to make the sound twice longer. To more realistically measure sound loudness, hearing sensitivity curves are used to measure sound loudness on a phon scale. Then, the 10th rule of thumb can be used to produce the sone scale of sound loudness. In particular, in measuring the sound level, weighting network filters such as weighting networks A, B, and C are used for measuring instruments like ear structure $(3,34)$.

\section{Sound loudness level (phon)}

Sound loudness unit is sone and sound loudness level is expressed by phon. In this study, the following equation was used to calculate the cumulative content (35):

SL $($ Phone $)=33.2 \log S+40$

Where $S L$ is the sound loudness level and $S$ is the absolute loudness or sone.

It was also found that sone is a function of the same curve that is obtained from the following equation:

$$
S t=I_{m}(1-k)+k \sum_{i=1}^{n} I_{i}
$$

(A)

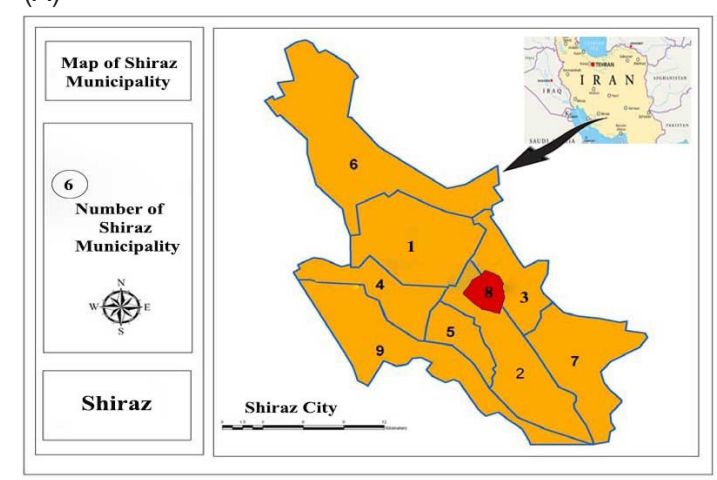

(B)

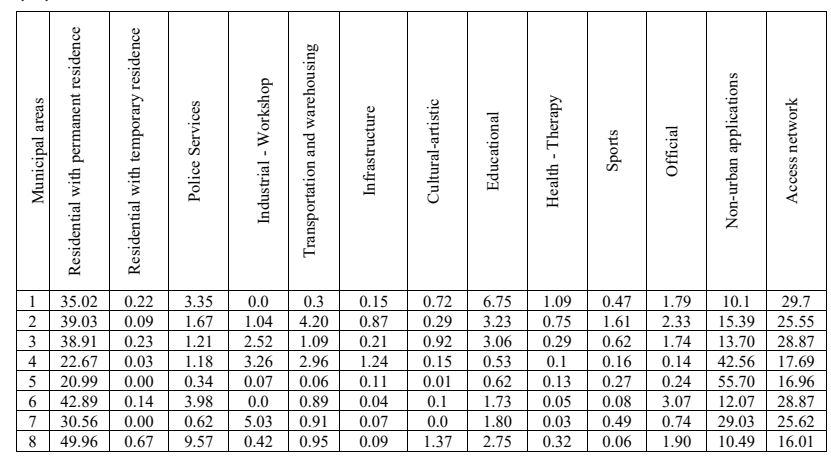

Figure 1. A) The population size of the passengers and pedestrians at public transportation stations of Shiraz during morning peak hours (adapted from studies by Shiraz Municipality in 2006). B) Percentage of urban land use in Shiraz city (reported by the city council in 2003). 
Where the total sum loudness $(S t)$, the maximum loudness $\left(I_{m}\right)$ and $I_{i}$ of each high value of the sound loudness (including the maximum peak) were obtained from the same magnitude curves and sound band weighting factor $(K)$ is equal to 0.3 for octave and 0.15 for one-third octave bands. Based on the results of previous studies and also using the following formula, the number of sampling stations was determined (36):

$$
n=\frac{Z_{\alpha / 2}{ }^{2} \times S^{2}}{d^{2}}
$$

Where a constant value $\left(Z_{\alpha / 2}\right)$ indicates the confidence level, $\alpha$, the error rate, in this case ( 0.3 for octave and 0.15 for $\mathrm{S} 2$, the prototype variance, and $d$, the measurement accuracy. The statistical calculations based on equation (3) showed that the 120 measurements may lead to 96 to 99\% accuracy and precision, which are more precise and also due to the possibility that a number of measurements may not be usable during the measurement. The number of measurements was $30 \%$ higher. The number of test stations was 156. The duration of calibration, according to ISO 9613 standard, determined for each measurement was about 90 seconds (37). Appropriate charts were produced using statistical analysis by Excel 2016 software.

In the next step, in order to measure the sound in the vicinity of highways and around the building, according to the Australian Standard Method, as well as the provisions of ISO 9613, first, the appropriate location was determined, then, according to ISO 9613, noise was measured (see Figure 2A and 2B) (38). The sound measurement positions were determined according to the EPA guidelines for accuracy and precision, not disturbing by airflow. Two sound level meters (TES-1358c, Taiwan) and (BSWA 308/309, class A and B, China) with the ability to measure LP, Leq, LN, SD, SEL, Max, Min, and Peak were used in this research. Calibration was carried out using a TES-1358C sound level calibrator, at each stage of the measurement. After sound measurement and frequency analysis, the TES-1358 was turned off and the results were accurately extracted from the memory of the machine and the manual data collection sheets and entered into the software (39).

The above-mentioned method has been confirmed by other researchers in terms of speed of measuring sound level and reducing waste of time but at high temperatures and altitudes, two important contradictions of microphone resistance against low temperatures and the impossibility of measuring sound level at high altitudes for accurate examination were observed. These contradictions were the main challenges to the present study.

Collected data were analyzed using Cox appropriatehazards model multivariate method. The Cox model is considered as a semi-parametric model for fitting the risk function. The relationship between the variables and survival time. The risk function for $\mathrm{X}$ variable is:
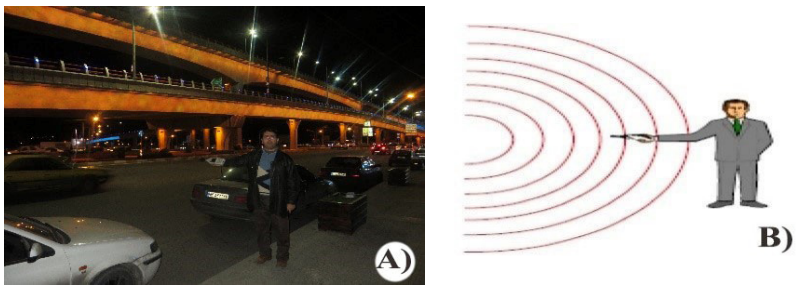

Figure 2. (A) Moalli Abad Bridge, measurement at 10 PM. (B) How to manually measure sound according to the Australian standard (38).

$\lambda(t ; x)=\lambda_{0}(t) \exp (x \beta)(4)$

Data were statistically analyzed using Minitab 18.1 and statistical significant level was considered at $P<0.05$. In order to predict the risk of hearing loss in citizens of the study areas, it was necessary to consider variables such as occupation, business experience, noise exposure, and smoking. Industrial results of risk assessment in previous studies showed that the higher the contact with disturbing and annoying sound, the greater the risk of cardiovascular disease and hearing loss will be. Cox regression model is one of the most widely used models for modeling the factors affecting the risk of various events by considering censored observations (40). In order to reduce the risk of hearing loss in a wide range of age with exposure to traffic noise, cultural and collaborative efforts to maintain and enhance hearing conservation programs are required.

\section{Results}

The results of environmental measurements in more than 156 points in the weighting network $\mathrm{A}$ and $\mathrm{C}$ are shown in Figure 3 and 4. According to these figures, all stations under study were at risk and no safety limit was recorded. The highest average sound pressure level belonged to the downtown and center stations and was equal to 83.3 $\mathrm{dB}$. It was also revealed that among 120 employees in the administrative center and 170 shopkeepers in this study, half of them had a history of hearing loss with a mean hearing threshold of $29.5 \pm 3.5 \mathrm{~dB}$. It should be noted that at the time of the measurement of the sound pressure level, no periodical or medical examination was performed and data were extracted only from the HSE departments and medical records. Work experience in the cases with normal hearing status was $5 \pm 1.2$ years and in those with hearing loss was $15 \pm 2.7$ years. As shown in Table 1, the risk of hearing loss in administrative workers was lower than that of commercial workers and taxi drivers. Here, the comparisons are purely with the environmental standards, not with occupational health standards.

Figure 3 shows the comparison of 7 different stations together. As shown in this table, the most frequency changes have been at frequencies below $150 \mathrm{~Hz}$. Figure 4 shows the change in sound pressure level $\left(\mathrm{L}_{\mathrm{p}}, \mathrm{C}\right)$ in slow mode in the study stations. The results suggest that 


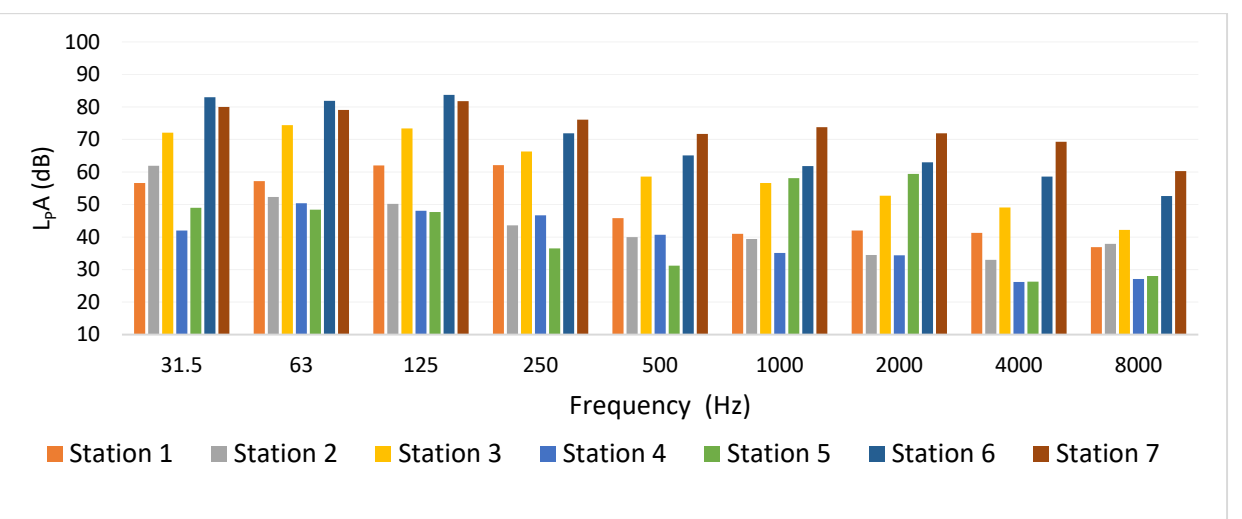

Figure 3. Sound pressure level $\left(L_{P} A\right)$ changes in the octave band weighting network in fast mode at 156 stations measured in Shiraz during 20152016.

(A)

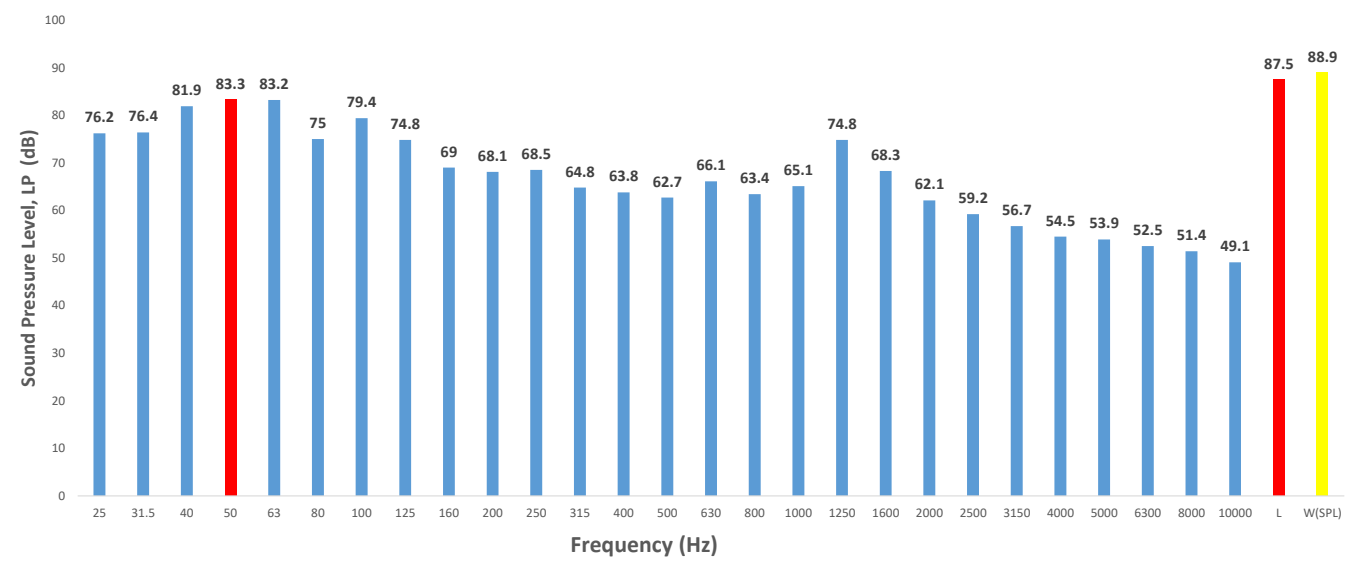

(B)

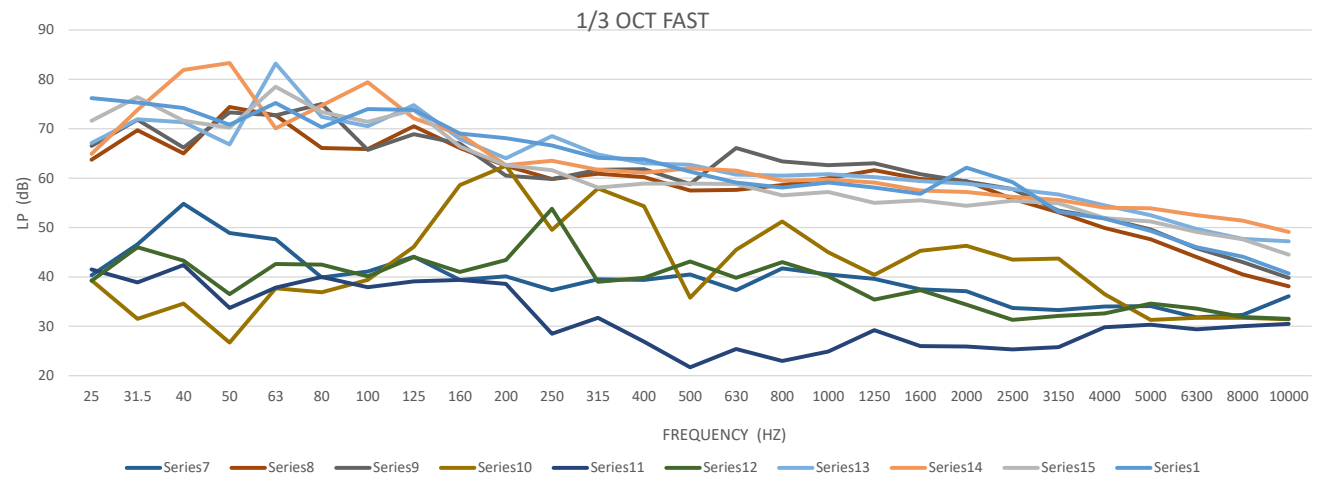

Figure 4. A) The maximum sound pressure level $\left(L_{p}, C\right)$ variations in one-third octave band weighting network in fast mode at 156 stations. B) Sound pressure level changes in one-third octave band weighting network in fast mode at 156 stations measured in Shiraz during 2015-2016.

changes in the sound pressure level varied from 27 to 88.4 $\mathrm{dB}$. According to Table 2, all results obtained from the study stations were higher than the Iran's environmental standard.

As shown in Figure 4, the highest level of sound pressure in a weighting system of one-third octave band was 83.33 $\mathrm{dB}$. This result showed that noise pollution was higher than the Iran's environmental standard. According to frequency analysis and conventional methods, intrusive frequency of traffic in Shiraz was less than $250 \mathrm{~Hz}$. The sound pressure level (LP) varied from 80 to $97.9 \mathrm{~dB}$ in these areas. The maximum and minimum level of LP were 88.9 and $53 \mathrm{~dB}$, respectively. Figures 3 and 4 show that the LP had a maximum level of $84.4 \mathrm{~dB}$, indicating 
Table 1. The variables affecting Noise-induced Hearing Loss (NIHL) using the Cox model in Shiraz citizens during 2015-2016

\begin{tabular}{lllcc}
\hline & Job Description & $\begin{array}{l}\text { Regression } \\
\text { Coefficient }(\boldsymbol{\beta})\end{array}$ & $\boldsymbol{P}$ value & Relative Risk \\
\hline Job Type & Taxi drivers & 1.10 & 0.042 & 3.36 \\
& Shop-keepers & 1.077 & 0 & 2.5 \\
& $\begin{array}{l}\text { Administrative- } \\
\text { commercial }\end{array}$ & 0.092 & - & 1.11 \\
& Commercial & 0.093 & 0.672 & 1.15 \\
Smoking & Smoker & 0.558 & - & 1.8 \\
Cigarettes & Non-smoker & - & - & 1.2 \\
\hline
\end{tabular}

Table 2. Free sound standards in Iran

\begin{tabular}{lcc}
\hline Zone Type & $\begin{array}{c}\text { Night: 10 PM to } 7 \text { AM } \\
\text { Leq (30), dB (A) }\end{array}$ & $\begin{array}{c}\text { Day: } 7 \text { AM to 10 PM } \\
\text { Leq (30), dB (A) }\end{array}$ \\
\hline Residential & 45 & 55 \\
Residential - Commercial & 50 & 60 \\
Commercial & 55 & 65 \\
Residential - Industrial & 60 & 70 \\
Industrial & 65 & 75 \\
\hline
\end{tabular}

Table 3. The noise rating equalizer in the octave band based on the ISO proposal

\begin{tabular}{lc}
\hline Range & Description \\
\hline$<15 \mathrm{~dB}$ & Very low level Zone \\
$15-45 \mathrm{~dB}$ & Comfort Zone \\
$>85 \mathrm{~dB}$ & Danger Zone \\
\hline
\end{tabular}

that the traffic noise violated the state noise standard for residential, commercial, and other areas (Tables 1-3). Figure 4 shows that the houses around the highways tolerated a high level of sound pressure $(88.4 \mathrm{~dB})$.

Noise pollution in large cities is a growing problem with the fact that the urban environment is becoming more crowded and noisy. In this study, the sound levels in the center of Shiraz were measured at 156 points along with 6 related streets. Simultaneously with noise measurements, the frequency analysis showed an annoying frequency of 50 to $250 \mathrm{~Hz}$. It was also revealed that the undesirable noise, the traffic noise and the crowd, were due to the noise of the streets and the construction. This result is consistent with the results of other studies. The findings showed an increase in traffic noise as reported by others. As shown in Figure 5, the cumulative sone in Shiraz with a maximum value was equal to 26 at several heavy traffic stations, while the calculations showed that the loudness level at two stations (11 and 12) was 87 phon. Transmission of data to the noise rating (NR) diagram showed that all stations except station 5 were in danger zones (Table 3 ).

At station 5, the results were higher than the comfort zone and less than the danger zone. In total, no area with lowfrequency sound pressure levels was observed. Analysis of sone and phon charts at a heavy traffic station using Excel 2016 software showed a gentle downward slope to high frequencies, this means that as we go towards lower frequencies, we see an increase in the amount of sone and sound loudness. This result is consistent with the results of low-frequency sound pressure levels (Figure 6).

For proper environmental risk analysis, the sound pressure level is compared with bulk curves and the environmental effects are determined. In this regard, the frequency ranged from 16 to $500 \mathrm{~Hz}$ was divided into two sections of 16 to $100 \mathrm{~Hz}$ and 125 to $500 \mathrm{~Hz}$. The frequency analysis along with the calculated sone and phon values are plotted in Figures 7 and 8 . These figures show that the Sone amount at frequencies below $20 \mathrm{~Hz}$ has constant level at heavy traffic stations, but with increasing frequencies to 31.5 and $40 \mathrm{~Hz}$ at five stations and in other cases at frequencies of 50 and $63 \mathrm{~Hz}$, it had the largest amount.

Data analysis showed that the sound loudness at both frequencies (below and above $100 \mathrm{~Hz}$ ) was high and lower values were observed in only four stations (Figure 7A and 7B). This fact clearly showed that sound loudness level was higher than the sound comfort, therefore, it was in danger range. Administrators, especially those who are involved in commercial and residential construction, can use the phon and sone charts for acoustic design of the buildings so that they can provide the quiet side for the users and consider the permissible environmental limit (Figures 7 and 8).

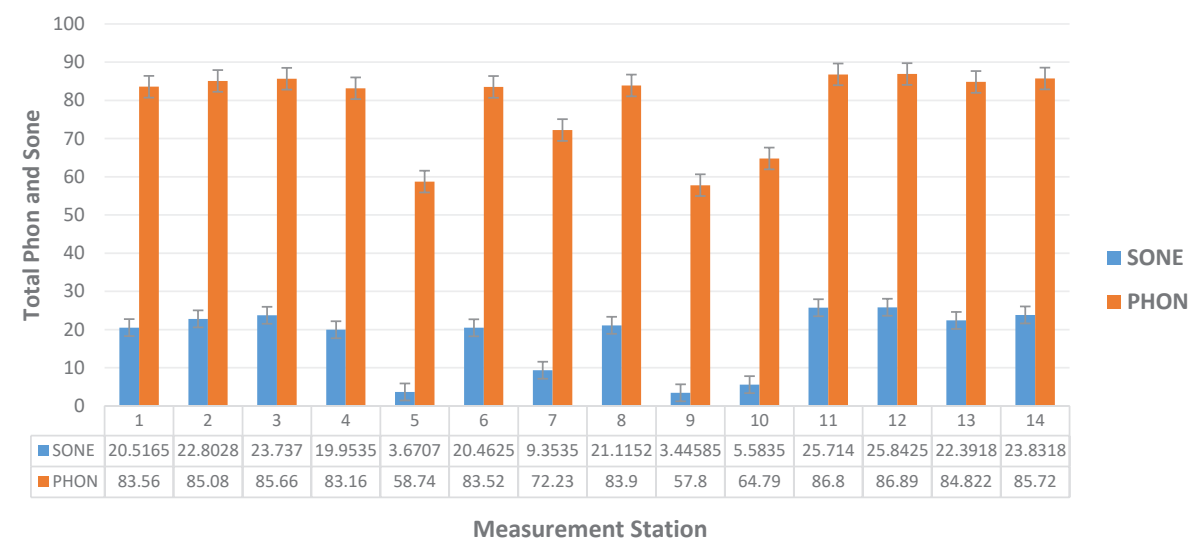

Figure 5. Cumulative phon and sone values of 14 heavy traffic stations in Shiraz during 2015-2016. 


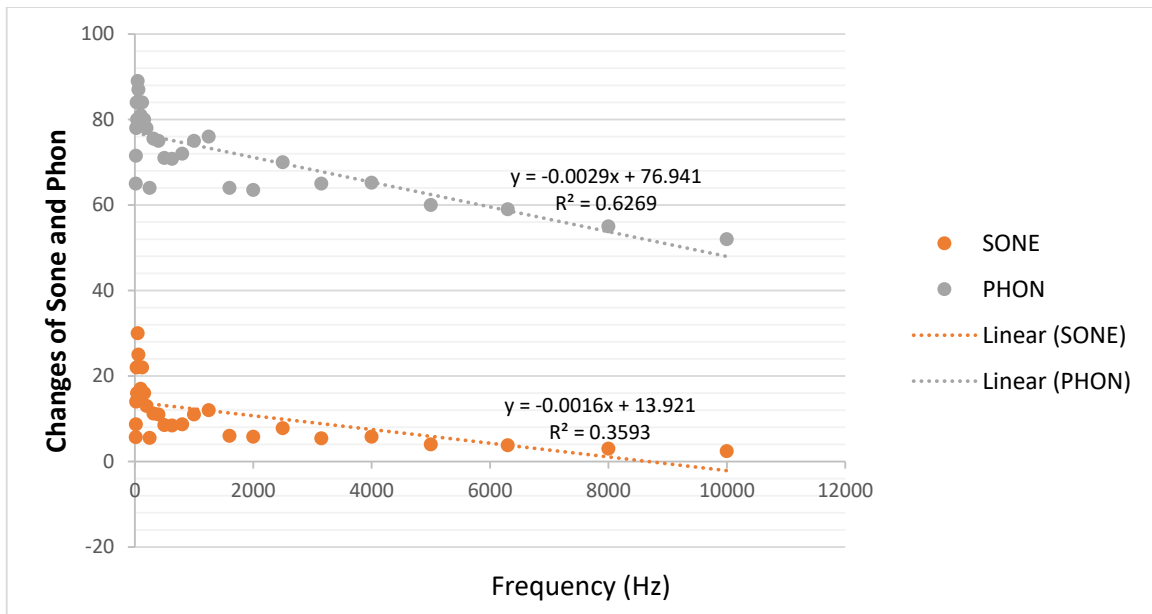

Figure 6. Linear changes of cumulative sone and phon of frequency at 14 heavy traffic stations in Shiraz during 2015-2016.
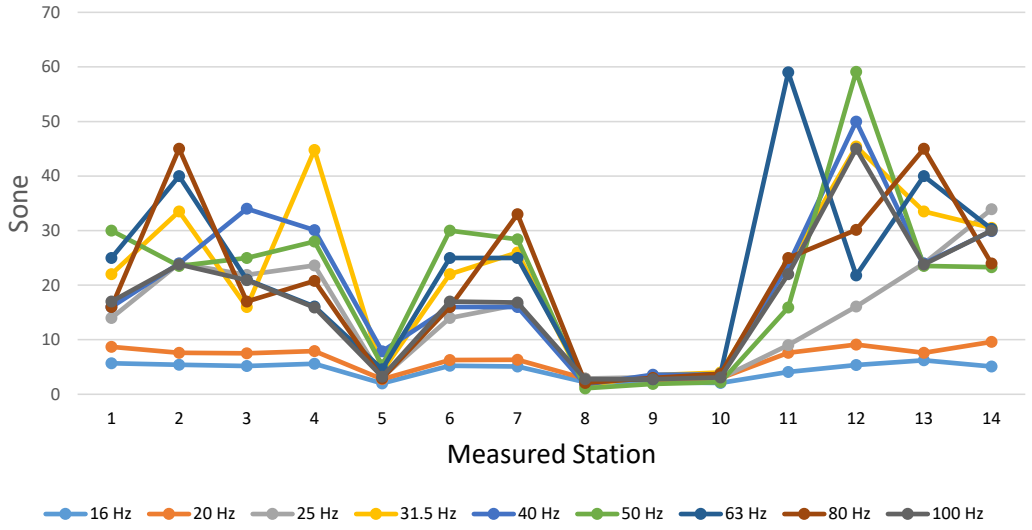

B

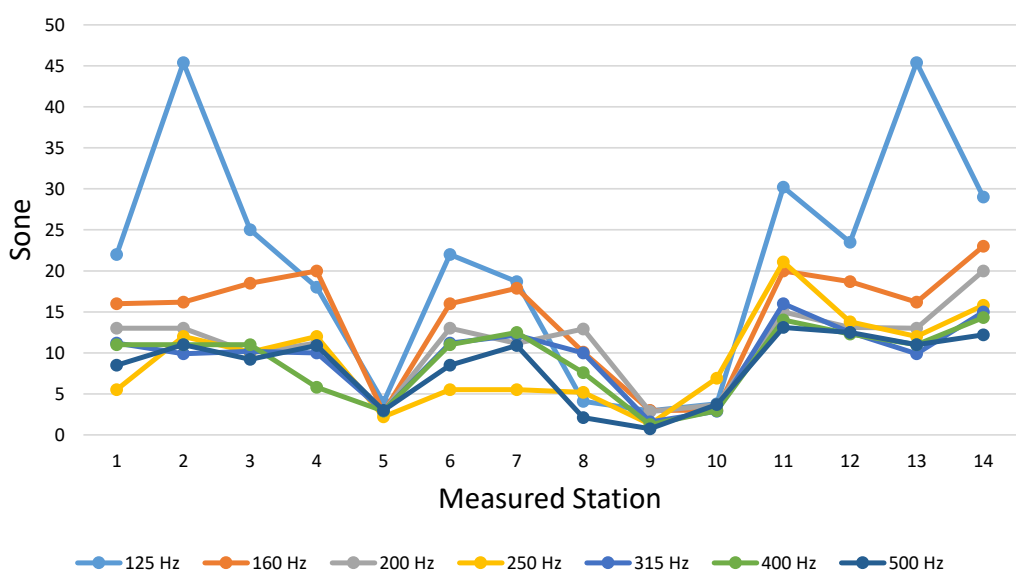

Figure 7. A) Sound loudness rate (sone) at frequencies below $100 \mathrm{~Hz}$ in Shiraz. B) Sound loudness rate (sone) at frequencies above $100 \mathrm{~Hz}$ in Shiraz during 2015-2016.

\section{Discussion}

Based on the analysis of the data obtained from the model, the amount of hearing loss in citizens exposed to sound depends on traffic habits, the presence of nearby sound generation resources, and other variables such as age, smokingbehavior, gender, and the use of personal protective equipment (that is not customary in the citizens). Hearing loss in the vicinity of noise centers increased, therefore, 
A

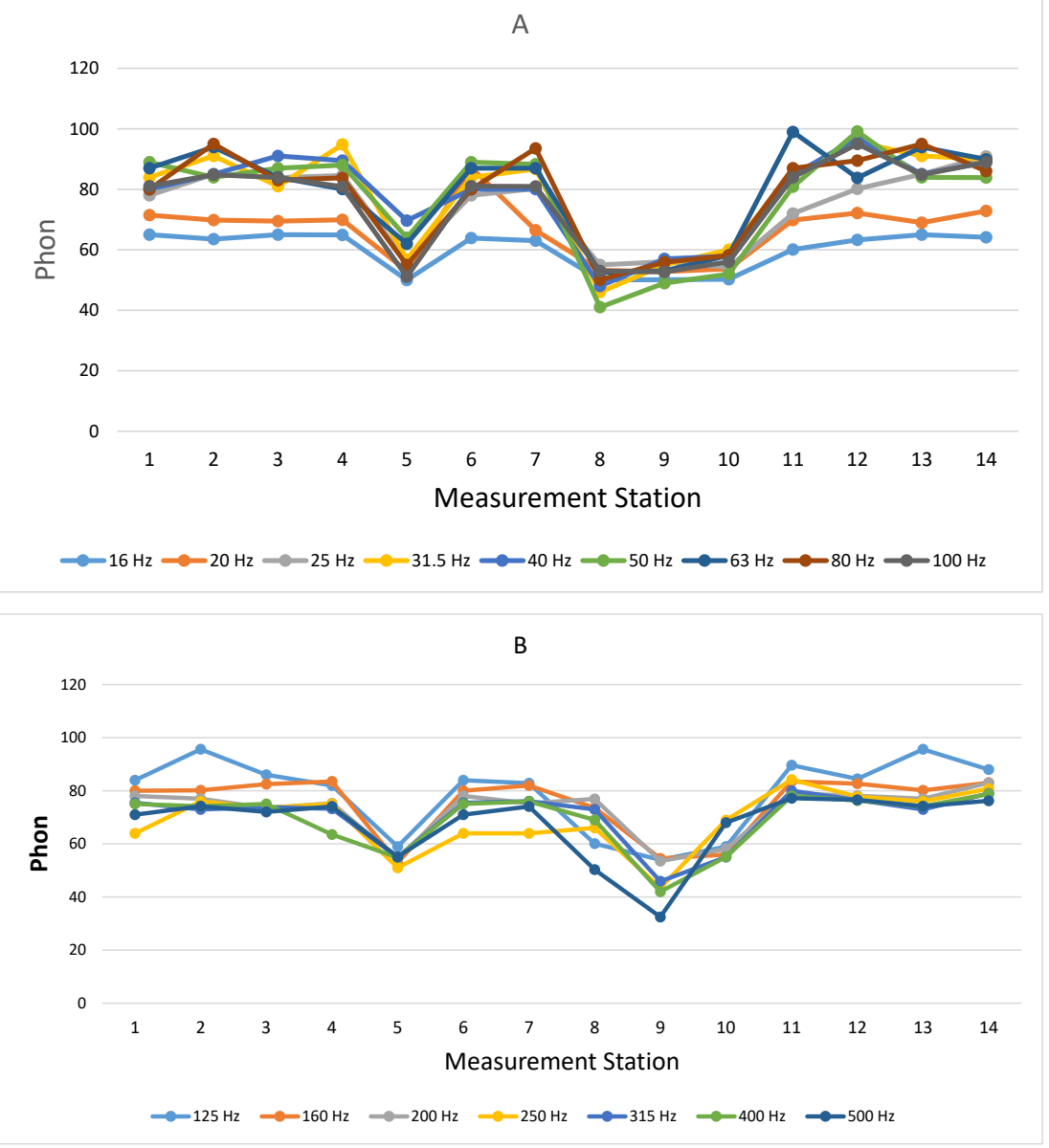

Figure 8. A) The rate of sound loudness level (phon) at frequencies below $100 \mathrm{~Hz}$ in 14 heavy traffic stations in Shiraz. B) The rate of sound loudness level (phon) at frequencies above $100 \mathrm{~Hz}$ in 14 heavy traffic stations in Shiraz during 2015-2016.

there is a need for a hearing conservation program as well as controlling and preventing noise transmission. Occupational variables and noise exposure had the most effect on the risk of hearing loss. High pressure levels of noise are one of the important variables in causing hearing loss.

As shown in Figure 4, the maximum frequency amount was below $1000 \mathrm{~Hz}(\mathrm{Max}=50 \mathrm{~Hz})$. Weighting network of the one-third octave band as a pre-requisite of planning of engineering designs, showed the highest changes in the sub-250 Hz range. According to Figure 1 and Table 1, if the citizens of Shiraz be considered in the central part of the city as commercial-residential, the environmental standard has not yet been observed and the results showed much higher values.

In shopkeepers, $\mathrm{L}_{\text {eq }}$ was equal to 83.7. According to the environmental standard in Iran, these values are higher than the standard. Because the use of personal protective equipment for hearing loss is not common in pe o ple, therefore, in order to predict the risk of hearing loss, only the daily exposure and smoking variables were considered. It seems that the results of this study while confirming the results of other researchers, showed a slight difference.
The research also showed an increase in noise pollution in Shiraz. The researchers were able to determine harmful environmental frequency of Shiraz traffic. So s one and phon were determined. It seems that the reason for these changes can be due to the following:

- Changing in the technology of making internal combustion engines with low-frequency output.

- The impact of high buildings on highway sound reflection and increasing the sound pressure level.

- Examining the index parameters with frequency analysis.

- Crowded cities with new noise resources.

It should be noted that in the past, a few research has pointed to harmful frequency, but many studies have been performed on the type of sound pressure level. To our knowledge, the sound pressure level does not generally reflect the frequency value. In any case, despite the above, noise was still recognized as a disturbing environmental factor.

\section{Conclusion}

Therefore, due to the high level of sound pressure level and the amount of sone and phon in Shiraz, noise pollution 
in the city has imposed economic and social costs and high risk on the citizens. Since the highest rate of noise pollution happened at low frequencies in Shiraz, therefore, low-frequency noise control with thin-layer adsorbents is very hard in this area. In this frequency range, no new sound absorber or sound control method (except classical methods with high cost and inconvenience, which in many cases are not applicable to buildings) has been introduced or applied in Iran. According to the results, the environmental and health risks in the city are clearly evident. The knowledge about the effect of low-frequency noise can help readers analogy this kind of effect with the results. The obtained results are consistent with the results of other studies (41-43).

The use of risk-based health impact assessment models on health such as Cox can be effective in analyzing relevant environmental data and decisions. According to ACGIH's reports, the errors of decentralization in both industrial and educational (office) sectors are clearly due to the effect of noise on the focus. Cox regression model well describes the quantitative effect of exposure conditions of citizens, especially workers who are permanently exposed to noise, on the risk of hearing loss. Accordingly, the noise in the environment of citizens has become a neglected factor in the large cities. The use of risk-forecasting tools and methods for controlling the sound transmission can provide useful information for planners and managers to improve traffic schedules and promote community health.

\section{Acknowledgements}

The authors would like to gratitude all people who have cooperated with the research team.

\section{Ethical issues}

The authors hereby certify that all data collected during the study is as stated in this manuscript, and no data from the study has been or will be published elsewhere separately.

\section{Competing interests}

The authors declare that they have no conflict of interests.

\section{Authors' contributions}

All authors contributed equally and were involved in the study design, data collection, and article approval.

\section{References}

1. Mansoori N. Environmental Pollution (Air, Water, Soil, Sound). Tehran: Etehad Publication; 2011. [In Persian].

2. John ME. Patties Industrial Hygiene and Toxicology. 3rd ed. USA: Wiley-inter Science Publication; 1978. p. 813-20.

3. Golmohammadi R. Sound and Vibration Engineering. Hamedan: Daneshjoo of Hamedan Publication; 1999. [In Persian].

4. Ohrstrom E, Skanberg A, Svensson H, Gidlof-Gunnarsson A. Effects of road traffic noise and the benefit of access to quietness. J Sound Vib 2006; 295(1-2): 40-59. doi: 10.1016/j. jsv.2005.11.034

5. Fiedler PE, Zannin PH. Evaluation of noise pollution in urban traffic hubs-noise maps and measurements. Environ Impact Assess Rev 2015; 51: 1-9. doi: 10.1016/j. eiar.2014.09.014.

6. Paravar A, Monazzam MR, Mansouri N, Motalebi Kashani M. Evaluation of noise pollution and traffic noise index using geographical information system in the main streets of Kashan, Iran. Health System Research 2015; 11(4): 68893. [In Persian].

7. Mirzaei R, Ansari-Moghaddam A, Mohammadi M, Rakhshani F, Salmanpor M. Noise pollution in Zahedan and residents' knowledge about noise pollution. Health Scope 2012; 1(1): 3-6. doi: 10.5812/jhs.4544.

8. Yari AR, Dezhdar B, Koohpaei A, Ebrahimi A, Mashkoori A, Mohammadi MJ, et al. Evaluation of traffic noise pollution and control solutions offering: a case study in Qom, Iran. Journal of Sabzevar University of Medical Sciences 2016; 23(4): 600-7. [In Persian].

9. Mosaferi M, Rasulzadeh Y, Nazari J, Taghipour H, Diyanat I. Study of noise pollution in downtown area of Tabriz during heavy traffic times. Medical Journal of Tabriz University of Medical Sciences 2012; 34(4):112-19. [In Persian].

10. Yousefzadeh A, Nassiri P, Rahimi Foroushani A. The relationship between air traffic noise and its induced annoyance in the southwest area in Tehran, Iran. Journal of Health and Safety at Work 2016; 6(3): 15-28. [In Persian].

11. Safari Variani A, Nikpay A, Ghalenoei M, Emamjomeh MM. Comparison of equivalent noise pollution and traffic noise index in different cities of Qazvin province (2010). Journal of Qazvin University of Medical Sciences 2013; 16(4): 69-74. [In Persian].

12. Ghanbari M, Nadafi K, Mosaferi M, Yunesian M, Aslani H. Noise pollution evaluation in residential and residentialcommercial areas in Tabriz-Iran. Iranian Journal of Health and Environment 2011; 4(3): 375-84. [In Persian].

13. Nadrian $\mathrm{H}$, Taghdisi $\mathrm{MH}$, Shojaeizadeh D, Nedjat S. Impacts of Sanandaj urban traffic and transport on social determinants of health from the perspective of key informants: a qualitative study. Journal of Education and Community Health 2018; 5(1): 49-60. doi: 10.21859/ jech.5.1.49. [In Persian].

14. Majidi F, Khosravi Y. Noise pollution evaluation of city center of Zanjan by Geographic Information System (GIS). Iranian Journal of Health and Environment 2016; 9(1): 91102. [In Persian].

15. Dehghan H, Gharib S. The effect of noise exposure on heart rate in the hot and humid conditions in climatic chamber. Journal of Occupational Hygiene Engineering 2016; 3(3): 1-8. doi: 10.21859/johe-03034. [In Persian].

16. Yaghoobi K, Alimohammadi I, Aboulghasemi J, Shirin Shandiz M, Aboutaleb N, Ashtari Nezhad A. The effect of noise on blood pressure and heart rate in an automotive industry. Journal of Occupational Hygiene Engineering 2016; 4(1): 26-34. doi: 10.21859/johe-04014. [In Persian].

17. Babamiri M, Motamedzadeh M, Golmohammadi R, Derakhshan J, Farhadian M. Role of personality type in the effects of low frequency sound on cognitive performance of the students. Journal of Occupational Hygiene Engineering 
2017; 4(2): 59-66. doi: 10.21859/ johe.4.2.59. [In Persian].

18. Soury S, Golmohamadi R. A review of the auditory and non-auditory effects of exposure to noise on women's health. Journal of Occupational Hygiene Engineering 2017; 4(2): 53-8. doi: 10.21859/johe.4.2.53. [In Persian].

19. Biabani A, Aliabadi M, Golmohamadi R. Study of performance of acoustic fixture for using in noise reduction rate tests of hearing protection devices. Journal of Occupational Hygiene Engineering 2016; 3(1): 60-6. doi: 10.21859/johe-03018. [In Persian].

20. Jafari S, Ansari H, Raee T, Mohammadian U, Hajizadeh R, Fazli B. Survey of noise-induced hearing loss among Fereidonkener taxi drivers in 2013. Journal of Health 2016; 7(1): 51-7. [In Persian].

21. Beheshti MH, Koohpaei A, Mousavian Z, Mehri A, Zia G, Tajpour A, et al. The effect of sound with different frequencies on selective attention and human response time. Iran Occupational Health Journal 2018; 15(3): 11828. [In Persian].

22. Mohammadi AK, Alidadi H, Delkhosh MB, Fallah $\mathrm{SH}$, Amouei A, Asgharnia $\mathrm{HA}$, et al. Noise pollution measurement in crowded areas of Neyshabur during primary three months of 2015. Journal of Research in Environmental Health 2016; 2(4): 276-84. [In Persian].

23. Zamanian Z, Azad P, Porkar S, Pirami H, Abdollahi M, Kouhnavard B. Study of noise pollution caused by traffic and its effect on sleep disturbances and quality of life for the citizens city of Shiraz. Occupational Medicine Quarterly Journal 2017; 8(4): 58-66.

24. World Health Organization (WHO). Global Health Observatory (GHO) data. [cited 2018 Aug 2] Available from: https://www.who.int/gho/publications/en/.

25. United States Environmental Protection Agency (US EPA). Information on levels of environmental noise requisite to protect public health and welfare with an adequate margin of safety. Washington DC: Government Printing Office; 1974.

26. Nwali EI, Agunwamba JC. Analysis of the environmental and socio-economic impact of noise pollution in ELEME petrochemical company limited. Nigerian Journal of Technology 2005; 24(1): 67-78.

27. Klaeboe R. Are adverse impacts of neighbourhood noisy areas the flip side of quiet area benefits? Appl Acoust 2007; 68(5): 557-75. doi: 10.1016/j.apacoust.2005.05.007.

28. Griefahn B, Brode P, Marks A, Basner M. Autonomic arousals related to traffic noise during sleep. Sleep 2008; 31(4): 569-77.

29. Griefahn B, Marks A, Robens S. Experiments on the time frame of temporally limited traffic curfews to prevent noise induced sleep disturbances. Somnologie 2008; 12(2): 140-8. doi: 10.1007/s11818-008-0341-0.

30. Raimbault M, Lavandier C, Berengier M. Ambient sound assessment of urban environments: field studies in two French cities. Appl Acoust 2003; 64(12): 1241-56. doi: 10.1016/S0003-682X(03)00061-6.

31. Dubois D, Guastavino C, Raimbault M. A cognitive approach to urban soundscapes: using verbal data to access everyday life auditory categories. Acta Acust United Acust 2006; 92(6): 865-74.

32. Botteldooren D, De Coensel B, De Muer T. The temporal structure of urban soundscapes. J Sound Vib 2006; 292(12): 105-23. doi: 10.1016/j.jsv.2005.07.026.

33. Luz GA. Maslow's hierarchy of needs as a model for the process of the development of national noise regulations. 9th International Congress on Noise as a Public Health Problem (ICBEN); 2008 Jul 21-25; ICBEN, USA; 2008.

34. Loudness - HyperPhysics Concepts. "Rule of Thumb" for Loudness. [cited 2018 May 28] Available from: http:// hyperphysics.phy-astr.gsu.edu/hbase/Sound/loud.html.

35. Kuttruff H. Acoustics, an Introduction. Translated by Abbassi AM. Tehran: Tehran University Publication; 2015. [In Persian].

36. Mohammadfam I. Research Design and Statistics for Safety and Health. Tehran: Fanavaran Publication; 2006. [Persian].

37. International Organization for Standardization (ISO). ISO 9613-2:1996. Acoustics -- Attenuation of sound during propagation outdoors -- Part 2: General method of calculation. Geneva, Switzerland: ISO; 1996.

38. Environmental Performance and Coordination Branch, Department of Environment and Heritage Protection. Noise Measurement Manual. [cited 2018 May 28] Available from: https://environment.des.qld.gov.au/licences-permits/ pdf/noise-measurement-manual-em1107.pdf.

39. TES Electrical Electronic Corp. Sound analyzer real time $1 \backslash 1$ and Octave band analysis. [cited 2018 Aug 3] Available from: http://www.tes.com.tw/en/product_detail. asp? seq $=380$.

40. Klein JP, Moeschberger ML. Survival Analysis: Techniques for Censored and Truncated Data. Springer Publication; 2003.

41. Moteallemi A, Bina B, Mortezaie S. Effects of noise pollution on Samen district residents in Mashhad city. Environmental Health Engineering and Management Journal 2018; 5(1): 23-7. doi: 10.15171/ehem.2018.04.

42. Mohammadi G. An investigation of community response to urban traffic noise. Iranian Journal of Environmental Health Science and Engineering 2009; 6(2): 137-42

43. Environmental Protection Agency (EPA). Guidance Note for Strategic Noise Mapping For the Environmental Noise Regulations 2006. [cited 2018 Nov 29] Available from: https://www.epa.ie/pubs/advice/noisemapping/EPA\%20 Guidance $\% 20$ Note $\% 20$ for $\% 20$ Strategic $\% 20$ Noise $\% 20$ Mapping\%20(version\%202).pdf. 